\title{
The classification of submerged vegetation using hyperspectral MIVIS data
}

\author{
Giuseppe Ciraolo, Eleanor Cox, Goffredo La Loggia and Antonino Maltese \\ Dipartimento di Ingegneria Idraulica ed Applicazioni Ambientali, Università degli Studi di Palermo, Italy
}

\begin{abstract}
The aim of this research is to use hyperspectral MIVIS data to map the Posidonia oceanica prairies in a coastal lagoon (Stagnone di Marsala). It is approximately $12 \mathrm{~km}$ long and $2 \mathrm{~km}$ wide and is linked to the open sea by two shallow openings. This environment is characterised by prairies of phanerogams, the most common of which is Posidonia oceanica, an ideal habitat for numerous species of fish, molluscs and crustaceans. A knowledge of the distribution of submerged vegetation is useful to monitor the health of the lagoon. In order to classify the MIVIS imagery, the attenuation effects of the water column have been removed from the signal using Lyzenga's technique. A comparison between classifications using indices obtained using band pairs from only the first spectrometer, and using band pairs of the first and second spectrometers, shows that the best classification is obtained from some indices derived from the first spectrometer. Field controls carried out in July 2002 were used to determine the training sites for the supervised classification. Twelve classes of bottom coverage were obtained from the classification, of which four are homogeneous and eight are mixed coverage. The methodology applied demonstrates that hyperspectral sensors can be used to effectively map submerged vegetation in shallow waters.
\end{abstract}

Key words water column correction - shallow water - hyperspectral imagery - submerged vegetation

\section{Introduction}

Mapping the density and distribution of benthic vegetation is valuable for the monitoring and management of coastal areas as discussed later. However it takes on a new significance in this study as the resulting classification of bottom types is required as an input to a hydrodynamic model of the site. The very shallow lagoon water means that water flow resistance and water exchange rates are very dependent on the submerged vegetation distribution, therefore the presence or absence of the phytobenth-

Mailing address: Dr. Goffredo La Loggia, Dipartimento di Ingegneria Idraulica ed Applicazioni Ambientali, Università degli Studi di Palermo, Viale delle Scienze, 90128 Palermo, Italy; e-mail: glal@idra.unipa.it ic community affects the velocity fields. The importance of taking different roughness coefficients into account during hydrodynamic modelling is confirmed by Balzano et al. (2001), and a knowledge of bottom cover distribution is therefore necessary. While similar research has been undertaken in the past using satellite imagery (Ackleson and Klemas, 1987; Armstrong, 1993; Ferguson and Korfmacher 1997), results have often been limited by the low spatial and spectral resolution of the sensors. This research presents the application of hyperspectral airborne remote sensing data, and as such both the spatial and spectral resolution are greatly improved. The aim of the research has been to improve past efforts to classify submerged vegetation in the coastal zone through the use of hyperspectral high resolution imagery and the application of the Lyzenga (1978, 1981) method to remove the attenuation effects of the water column from the results.

Much research has been undertaken (Lyzenga, 1978, 1981; Ackleson and Klemas, 1987; 
Armstrong, 1993; Ferguson and Korfmacher, 1997; Mumby et al., 1998; Durand et al., 2000; Holden and LeDrew, 2002; Dierssen et al., 2003; Louchard et al., 2003) using either satellite or aerial remote sensing data to study the distribution of benthic vegetation, coral or bed type in coastal areas. Many of these studies have not attempted to take the attenuation effects of the overlying water column into account, however others have used a variety of approaches to reduce the effects of the water column. These approaches include the use of empirically based models based on field spectrometry measurements (Holden and LeDrew, 2002; Dierssen et al., 2003), radiative transfer modelling (Louchard et al., 2003), or applications of the technique outlined by Lyzenga (1978, 1981). Dierssen et al. (2003) provide a detailed critique of the methods available to remove water column effects from remotely sensed data; however, they fail to provide a solution that does not rely on an external data source such as in situ measurements. Durand et al. (2000) provide an inverse model to determine bathymetry, bottom coverage, water column reflectance spectra and a water clarity assessment from remotely sensed imagery of coastal areas, however they too rely on a detailed database of environmental properties. Mumby et al. (1998) applied the Lyzenga approach for the mapping of coral reefs, and found that while it has not been widely adopted by the remote sensing community, it produced significantly better results. The main disadvantage stated in using the Lyzenga (1981) method is that it is only reliable in clear waters and that most coastal waters are turbid (Durand et al., 2000).

\section{Study area}

The study area (shown in fig. 1) is the Stagnone di Marsala, located on the west coast of Sicily in the Province of Trapani. It is a coastal lagoon with an area of approximately 2000 hectares, it is about $12 \mathrm{~km}$ long and the depth varies from 20 to $300 \mathrm{~cm}$. The lagoon is linked to the open sea by a narrow, shallow opening to the north, and a wider opening to the south. For this reason, there are two sub-basins: a Northern
Basin characterised by shallow water and low water exchange due to the restrictive nature of the northern opening; and a deeper Southern Basin characterised by higher water exchange rates. The morphology of the lagoon protects it from the high wave energy of the open sea, and therefore the water has very low turbidity. The warm, shallow water provides an ideal habitat for a variety of submerged vegetation, fish, molluscs, crustaceans and a wide range of bird life. There is a high species diversity and as such the lagoon is of great environmental importance, it has been designated as a nature reserve.

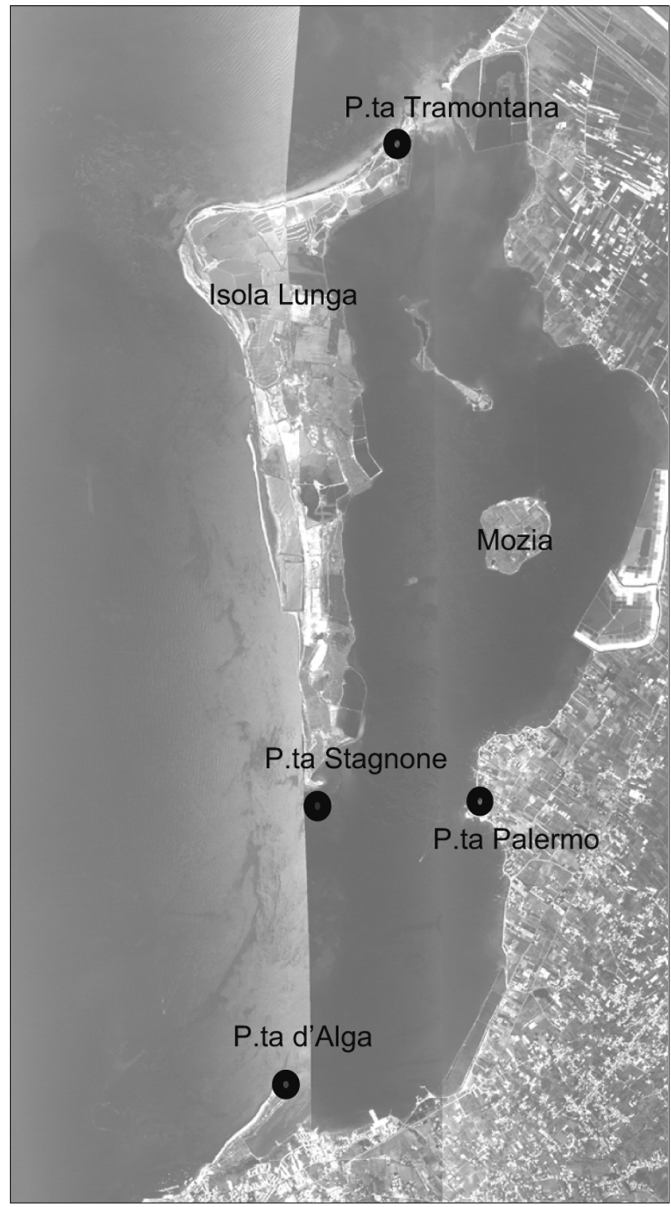

Fig. 1. Study area - MIVIS image 1994. 
Several types of vegetation thrive in the shallow water of the lagoon, however the dominating species are phanerogams including Posidonia oceanica, Caulerpa prolifera and Cymodocea nodosa. Where the environmental conditions are favourable, these species tend to form broad prairies. Submerged vegetation is a stabilising factor in the dynamic coastal environment; it reduces erosion of the sea floor and protects the coast through the attenuation of wave energy. In addition these submerged prairies provide a sheltered habitat for a wide range of fish and other marine life, and are often used as breeding grounds. Furthermore, the mapping of these macrophytes is valuable as they are very sensitive to changes in water quality, currents and other environmental conditions, and therefore an understanding of the distribution and dynamics of these species is essential to monitor changing conditions and to support future decisions for the management of the Nature Reserve.

Field observations on the type and distribution on benthic vegetation have been carried out in previous years, with floating dead seagrass found in several areas of the lagoon, Posidonia oceanica in atoll formations and a zone of emergent Posidonia oceanica to the south (Calvo et al., 1980). While field surveys are useful for the mapping of the lagoon, remote sensing techniques could provide a quicker, more accurate and cost effective approach. Moreover, once the techniques have been refined, they could be used to build up a time series of data to monitor changes in the lagoon. Such monitoring is necessary to determine any effects of climate change or anthropic stress, since the lagoon is under pressure from growing urbanisation along the coast.

\section{Method}

\subsection{Available data}

Remotely sensed images from the airborne Deadalus AA5000 Multispectral Infrared Visible Imaging Spectrometer (MIVIS) sensor in July 1994 have been used for this research. This sensor was managed by the CNR (Con- siglio Nazionale delle Ricerche - National Research Council) for the LARA (Laboratorio Aereo Ricerche Ambientali - Aerial Laboratory for Environmental Research) project, aimed at monitoring and controlling the environment. It is a whiskbroom sensor with high spatial (IFoV $0.2 \mathrm{mrad})$, spectral $(0.02 \mu \mathrm{m}$ and $0.05 \mu \mathrm{m}$ for the first and second spectrometer respectively) and radiometric (12 bit) resolution. The high spatial resolution of this sensor makes it ideal for research on a study area of this scale, with the ground resolution at nadir for an average flight height of $2000 \mathrm{~m}$ being $4 \mathrm{~m}$. The MIVIS is a hyperspectral sensor with 102 bands distributed within the visible and infrared regions of the spectrum between 0.43 and $12.7 \mu \mathrm{m}$. Of the bands available, we have only used the first 28 bands, which make up the first and second spectrometer. The twenty bands in the first spectrometer have been chosen since they have shorter wavelengths and therefore have the greatest penetration in water, while the eight bands in the second spectrometer were chosen to aid detection of floating or emergent vegetation in very shallow water. In addition, thermal infrared bands from the fourth spectrometer were used for the logical masking of land areas in the images. Since the thermal bands are characterised by a bimodal histogram with a strong separation between the sea and the land we chose the minimum value between the two peaks as a threshold to mask the land area.

\subsection{Water column correction}

The MIVIS images, already corrected for radiometric effects were first georeferenced, and then corrected for atmospheric scattering and the external reflection from the water surface. These preprocessing techniques are commonly used in all studies of the coastal environment. However, to extract more accurate information on the types of bed coverage, the images have also been corrected for the attenuation of reflectance linked to the water depth. The method adopted is that of Lyzenga (1978, 1981), whereby a depth invariant index of bottom type is defined as a function of the water surface reflectance from two spectral bands and ratios of the water attenuation coeffi- 
cients for the wavelength band pairs used. This index can then be used to classify the bottom types found in the study area.

In order to calculate this index, a simplified radiative transfer equation is used. Lyzenga (1978) simplified an original radiative transfer equation (Jain and Miller, 1977) in terms of radiance to

$$
L_{0}\left(\lambda_{i}\right)=L_{\infty}\left(\lambda_{i}\right)+\left[\left(L_{b}\left(\lambda_{i}\right)-L_{\infty}\left(\lambda_{i}\right)\right)\right] \cdot e^{\left(-2 K_{d}\left(\lambda_{i}\right) z\right)}
$$

where $L_{0}\left(\lambda_{i}\right)$ is the radiance just below the water surface; $L_{\infty}\left(\lambda_{i}\right)$ is the radiance value of an infinitely deep water column; $L_{b}\left(\lambda_{i}\right)$ is the bottom radiance; $K_{d}\left(\lambda_{i}\right)$ is the diffuse attenuation coefficient; $z$ is the water depth.

The site chosen to measure $L_{\infty}$ is found in the deep water to the south-west of the Stagnone.

All of the parameters except depth vary with wavelength, so it is possible to modify the equation further to linearise the dependence of radiance on depth using a logarithmic transformation, and then determine the relationship of the remaining parameters for band pairs.

The first step requires the transformation of eq. (3.1) in order to linearise the dependence of measured reflectance on water depth. Therefore, for two different wavelengths, $i$ and $j$

$$
\begin{aligned}
& X_{i}=\ln \left[L_{0}\left(\lambda_{i}\right)-L_{\infty}\left(\lambda_{i}\right)\right]= \\
& =\ln \left[L_{b}\left(\lambda_{i}\right)-L_{\infty}\left(\lambda_{i}\right)\right]-2 K_{d}\left(\lambda_{i}\right) z \\
& X_{j}=\ln \left[L_{0}\left(\lambda_{j}\right)-L_{\infty}\left(\lambda_{j}\right)\right]= \\
& =\ln \left[L_{b}\left(\lambda_{j}\right)-L_{\infty}\left(\lambda_{j}\right)\right]-2 K_{d}\left(\lambda_{j}\right) z .
\end{aligned}
$$

Rearranging these two equations in order to remove the depth variable, we obtain:

$$
X_{j}=\frac{K_{d}\left(\lambda_{i}\right)}{K_{d}\left(\lambda_{j}\right)} \cdot X_{i}+\ln \frac{\left[L_{b}\left(\lambda_{i}\right)-L_{\infty}\left(\lambda_{i}\right)\right]}{\left[L_{0}\left(\lambda_{j}\right)-L_{\infty}\left(\lambda_{j}\right)\right]^{\frac{K_{d}\left(\lambda_{i}\right)}{K_{d}\left(\lambda_{j}\right)}}}
$$

A linear relationship between $X_{i}$ and $X_{j}$ for a homogenous bottom type means that the logarithmic term is constant and can therefore be used as a depth invariant bottom type index

$$
\text { index }=X_{i}-\frac{K_{d}\left(\lambda_{i}\right)}{K_{d}\left(\lambda_{j}\right)} \cdot X_{j}
$$

or,

$$
\begin{aligned}
& \text { index }=\ln \left[L_{0}\left(\lambda_{i}\right)-L_{\infty}\left(\lambda_{i}\right)\right]-\frac{K_{d}\left(\lambda_{i}\right)}{K_{d}\left(\lambda_{j}\right)} . \\
& \cdot \ln \left[L_{0}\left(\lambda_{j}\right)-L_{\infty}\left(\lambda_{j}\right)\right] .
\end{aligned}
$$

Equation (3.1) written by Lyzenga (1978) in terms of radiance has also been written by Ben Moussa et al. (1989) in terms of reflectance. The procedure to determine indices described above can therefore also be applied in terms of reflectance, with the advantage of obtaining values independent from the geometry of solar illumination (azimuth, elevation) and from the downwelling radiance at the time of acquisition, only being dependent on the bottom characteristics. So, eq. (3.6) can be written

$$
\begin{aligned}
& \text { index }=\ln \left[R_{0}\left(\lambda_{i}\right)-R_{\infty}\left(\lambda_{i}\right)\right]-\frac{K_{d}\left(\lambda_{i}\right)}{K_{d}\left(\lambda_{j}\right)} . \\
& \cdot \ln \left[R_{0}\left(\lambda_{j}\right)-R_{\infty}\left(\lambda_{j}\right)\right] .
\end{aligned}
$$

This method assumes that $K_{d}\left(\lambda_{i}\right)$ is spatially constant given an invariant level of turbidity. The diffuse attenuation coefficient, $K_{d}\left(\lambda_{i}\right)$, differs depending on whether downwelling or upwelling radiance is considered, however the use of the term $2 K_{d}$ in eqs. ((3.1)-(3.3)) assumes that the diffuse attenuation coefficient is constant, and is doubled to take into account the downward and upward paths of light through the water column. This assumption of constant attenuation is an important factor regarding the accuracy of reflectance derived from the model proposed.

Assuming that the ratio of $K_{d}(\lambda)$ depends only on the water column characteristics, it is possible to calculate its value plotting the logarithmic term of band $i$ against the logarithmic term of band $j$. To this aim we used formulae minimising the mean square deviation perpendicular to the regression line as proposed by Edwards and Mumby (1999)

$$
\frac{K_{d}\left(\lambda_{i}\right)}{K_{d}\left(\lambda_{j}\right)}=a+\sqrt{a^{2}+1}
$$


where

$$
a=\frac{\sigma_{i}-\sigma_{j}}{2 \sigma_{i j}}
$$

and $\sigma_{i}$ and $\sigma_{j}$ are the variances relating to the transformed images $X_{i}$ and $X_{j}$, and $\sigma_{i j}$ is the covariance between the transformed images $X_{i}$ and $X_{j}$. The gradient of the straight line obtained is equal to the ratio $K_{d}\left(\lambda_{i}\right) / K_{d}\left(\lambda_{j}\right)$, representing the relative attenuation for radiation at these two wavelengths.

By plotting the images $X_{i}$ against $X_{j}$, the index of a homogenous bottom type relating to two bands is represented by the $y$-axis intercept; if the bottom type changes, the value of the intercept changes. Graphically the lines that represent each homogeneous bottom are parallel, since the ratio $K_{d}\left(\lambda_{i}\right) / K_{d}\left(\lambda_{j}\right)$ is constant. Using a graphical interpretation of eq. (3.6), the pixels in the clusters of homogenous bottom types have been projected to the $y$-axis in the direction determined by the regression line. The $y$ axis thus assumes a new significance in which the generic value $\overline{O Y}$ is the homogenous bottom index, and the maximum value of the $n$th cluster $(\overline{O Y})_{n}$ values on a frequency histogram correspond to the regression line. The indices of two band pairs have a Gaussian distribution, the indices of three band pairs form ellipsoids, and so on in $n$-dimensional space. A classification to identify areas with homogenous bottom coverage and field surveys to assign the generic bottom type index is therefore necessary.

\subsection{Comparison of various band pairs}

Table I shows the ratios of the diffuse attenuation coefficient for the first 16 bands of the MIVIS images. Bands with wavelengths greater than $0.75 \mu \mathrm{m}$ gave poor results since there is greater absorption of the red part of the spectrum in the water column so the results are not reliable. Some band pairs were found to provide better results for the mapping of submerged vegetation (highlighted in grey), so these bands have been used for further classification.

\subsection{Classification}

As explained above, different bottom types form different clusters in $n$-dimensional space; however the boundaries of these clusters are not

Table I. Diffuse attenuation coefficient ratios.

\begin{tabular}{cccccccccccccccc}
\hline \hline Band $K$-ratio & $\mathbf{1}$ & $\mathbf{2}$ & $\mathbf{3}$ & $\mathbf{4}$ & $\mathbf{5}$ & $\mathbf{6}$ & $\mathbf{7}$ & $\mathbf{8}$ & $\mathbf{9}$ & $\mathbf{1 0}$ & $\mathbf{1 1}$ & $\mathbf{1 2}$ & $\mathbf{1 3}$ & $\mathbf{1 4}$ & $\mathbf{1 5}$ \\
\hline $\mathbf{2}$ & 0.75 & - & - & - & - & - & - & - & - & - & - & - & - & - & - \\
$\mathbf{3}$ & 0.68 & 0.92 & - & - & - & - & - & - & - & - & - & - & - & - & - \\
$\mathbf{4}$ & 0.64 & 0.86 & 0.94 & - & - & - & - & - & - & - & - & - & - & - & - \\
$\mathbf{5}$ & 0.60 & 0.81 & 0.88 & 0.94 & - & - & - & - & - & - & - & - & - & - & - \\
$\mathbf{6}$ & 0.54 & 0.72 & 0.79 & 0.84 & 0.90 & - & - & - & - & - & - & - & - & - & - \\
$\mathbf{7}$ & 0.49 & 0.67 & 0.73 & 0.78 & 0.83 & 0.93 & - & - & - & - & - & - & - & - & - \\
$\mathbf{8}$ & 0.46 & 0.63 & 0.69 & 0.73 & 0.79 & 0.88 & 0.95 & - & - & - & - & - & - & - & - \\
$\mathbf{9}$ & 0.44 & 0.60 & 0.66 & 0.70 & 0.75 & 0.84 & 0.91 & 0.96 & - & - & - & - & - & - & - \\
$\mathbf{1 0}$ & 0.43 & 0.58 & 0.64 & 0.68 & 0.73 & 0.82 & 0.89 & 0.94 & 0.98 & - & - & - & - & - & - \\
$\mathbf{1 1}$ & 0.43 & 0.59 & 0.65 & 0.69 & 0.74 & 0.83 & 0.90 & 0.95 & 0.98 & 1.01 & - & - & - & - & - \\
$\mathbf{1 2}$ & 0.43 & 0.59 & 0.65 & 0.69 & 0.74 & 0.83 & 0.89 & 0.94 & 0.98 & 1.01 & 1.00 & - & - & - & - \\
$\mathbf{1 3}$ & 0.43 & 0.59 & 0.65 & 0.69 & 0.74 & 0.83 & 0.90 & 0.95 & 0.99 & 1.01 & 1.00 & 1.01 & - & - & - \\
$\mathbf{1 4}$ & 0.45 & 0.62 & 0.68 & 0.72 & 0.78 & 0.87 & 0.94 & 1.00 & 1.04 & 1.06 & 1.05 & 1.06 & 1.05 & - & - \\
$\mathbf{1 5}$ & 0.49 & 0.67 & 0.74 & 0.79 & 0.85 & 0.96 & 1.04 & 1.10 & 1.14 & 1.17 & 1.16 & 1.16 & 1.15 & 1.09 & - \\
$\mathbf{1 6}$ & 0.39 & 0.54 & 0.60 & 0.64 & 0.70 & 0.79 & 0.86 & 0.91 & 0.95 & 0.98 & 0.97 & 0.97 & 0.96 & 0.92 & 0.84 \\
\hline
\end{tabular}


Table II. Field truth data.

\begin{tabular}{|c|c|c|c|}
\hline $\begin{array}{l}\text { Field truth data } \\
\text { UTM ED50 }\end{array}$ & $\underset{[\mathrm{m}]}{X \text {-coordinate }}$ & $\begin{array}{c}Y \text {-coordinate } \\
{[\mathrm{m}]}\end{array}$ & Bottom cover type \\
\hline 1 & 276788 & 4190466 & Sand \\
\hline 2 & 276830 & 4190478 & Sand \\
\hline 3 & 274016 & 4190031 & Posidonia oceanica reef-plateau \\
\hline 4 & 275491 & 4188303 & Dead matte (Punta d'Alga) \\
\hline 5 & 275407 & 4191759 & Dead matte (Isola Lunga) \\
\hline 6 & 277828 & 4193334 & Absence of vegetation due to boats passing in continuation \\
\hline 7 & 273070 & 4194745 & Erosion channel in Posidonia oceanica \\
\hline 8 & 275026 & 4190562 & Emergent Posidonia oceanica \\
\hline 9 & 275962 & 4195746 & Cymodocea nodosa and Caulerpa prolifera \\
\hline 10 & 276295 & 4196169 & Cymodocea nodosa \\
\hline
\end{tabular}
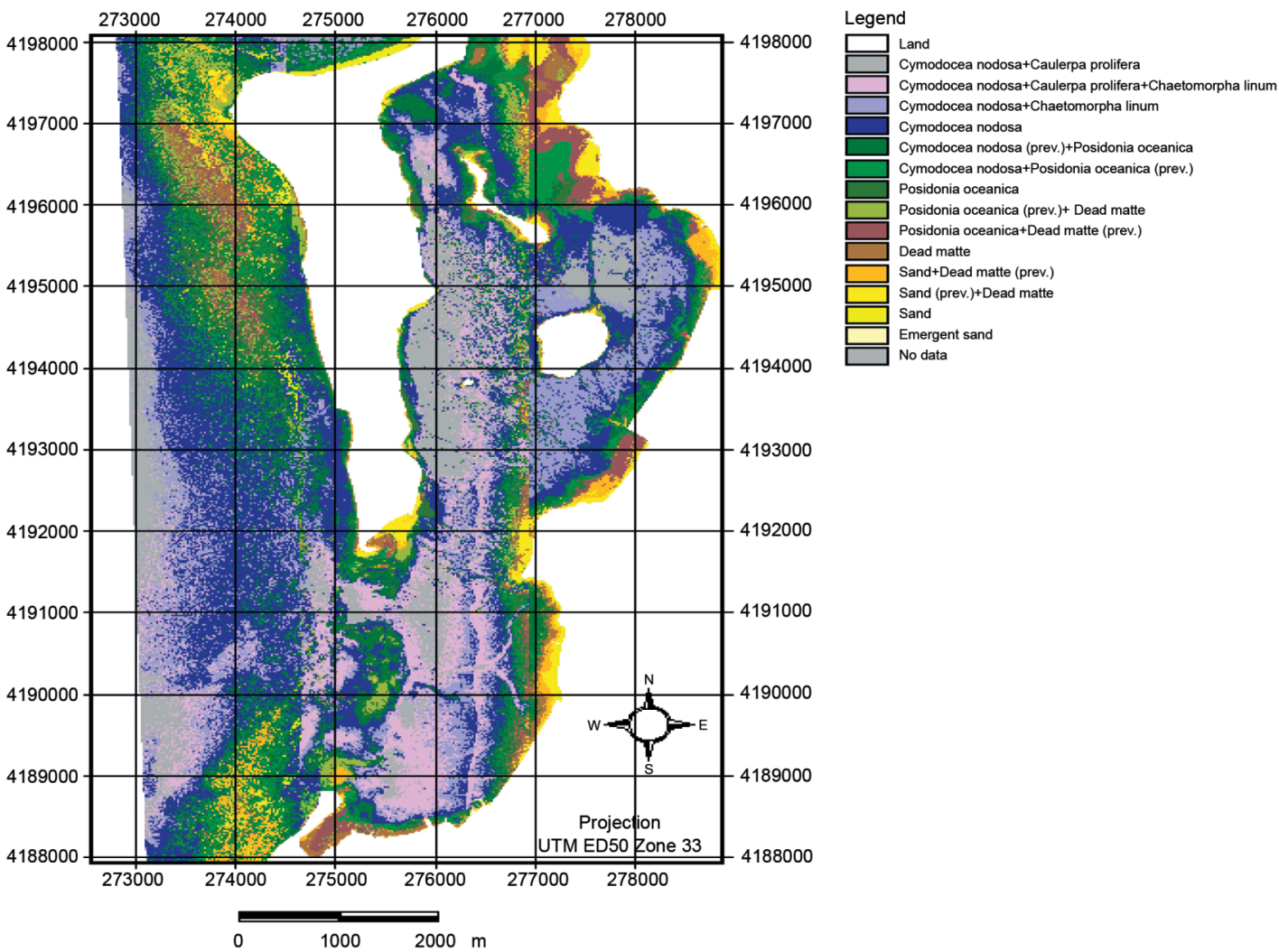

Fig. 2. Map of bottom types. 
well defined since there are transitional areas, so although the Lyzenga indices represent homogeneous bottom types, further classification is necessary. The land present in the image was masked, leaving only the coastal water of the study area to reduce the variability in digital numbers, increasing the contrast in the zone being studied. This was necessary to improve the visual interpretation of the images during the identification of training sites. Care was taken not to classify different plant densities as different species, since spectral response varies with plant density. Once the training sites were selected, the benthic vegetation was mapped using maximum likelihood classification. Field truth data collected in the summer of 2002 were used to assign bottom cover type to the classes identified as shown in table II.

\section{Results}

The results of the maximum likelihood classification (fig. 2) show a prevalence of Cymodocea nodosa and Caulerpa prolifera in the northern sub-basin with Posidonia oceanica in atoll formations and a reef barrier between Punta dello Stagnone and Punta di Palermo. The classification also identifies emergent sand near Punta di Tramontana. The results in the southern sub-basin confirm the presence of an emergent Posidonia oceanica prairie, while Cymodocea nodosa remains dominant. Dead Posidonia oceanica and sand banks have been identified between Punta dello Stagnone and Punta d'Alga. Off the shores of Isola Lunga outside the lagoon there are Posidonia oceanica prairies divided by several erosion channels and emergent sand to the north-west of the island.

\section{Conclusions}

The Lyzenga method is proposed as an alternative to water column correction using the Ben Moussa et al. (1989) equation. The latter requires a knowledge of the bathymetry and attenuation coefficients with varying wavelengths, moreover even a slight error in the bathymetry causes substantial over-correction of the influ- ence of the water column since bathymetry is in the exponential term of the radiative transfer eq. (3.1). The results of the classification appear to show that in some cases the classes are distributed according to changes in the illumination of the images from nadir towards the extremes of the field of view. For example, errors in the classification identified through the field truth data were caused by the over-illumination of the eastern border of the images. Current work is aimed at correcting images for these effects of sunglint and uneven illumination using the bands from the second spectrometer of the MIVIS sensor. The high spatial and spectral resolution MIVIS images reduced the difficulty in distinguishing between often mixed seagrass species. In conjunction with the Lyzenga method to correct for the effects of the water column, this study has shown that hyperspectral imagery can be successfully applied to mapping bottom types in shallow water.

\section{Acknowledgements}

We would like to thank the LARA (Laboratorio Aereo Ricerche Ambientali) project for providing the MIVIS images, in the framework of the MIR project funded by MIUR. We also appreciate the help of C. La Mantia, E. Bellini, and R. Sciortino for data processing.

\section{REFERENCES}

AcKLeson, S.G. and V. Klemas (1987): Remote sensing of submerged vegetation in lower Chesapeake Bay: a comparison of Landsat MSS to TM imagery, Remote Sensing Environ., 22, 235-248.

Armstrong, R.A. (1993): Remote sensing of submerged vegetation canopies for biomass estimation, Int. J. Remote Sensing, 14, 621-627.

Balzano, A., G. Ciraolo, G. La Loggia and G. Viviani (2001): Using hydrodynamic-transport numerical models and remote sensing to manage coastal lagoon environments, presented at the III International Symposium on Environmental Hydraulics, 5-8 December 2001, Tempe (Arizona).

Ben Moussa, H., M. Viollier and T. Belsher (1989): Télédétection des algues macrophytes de l'Archipel de Molène (France) Radiométrie de terrain et application aux données du satellite SPOT, Int. J. Remote Sensing, 10 (1), 53-69.

Calvo, S., D. Drago and M. Sortino (1980): Winter and 
summer submersed vegetation maps of the Stagnone (western coast of Sicily), Rev. Biol.-Ecol. Méditerr., 7 (2), 89-96.

Dierssen, H.M., R.C. Zimmerman, R.A. Leathers, T.V. Downes and C.O. DAVIS (2003): Ocean color remote sensing of seagrass and bathymetry in the Bahamas Banks by high-resolution airborne imagery, Limnol. Oceanogr., 48 (1), 444-455.

Durand, D., J. BiJAOUi and F. CAUnEAu (2000): Optical remote sensing of shallow-water environmental parameters: a feasibility study, Remote Sensing Environ., 73, $152-161$.

Edwards, A.J. and P.J. Mumby (1999): Compensating for variable water depth to improve mapping of underwater habitats: why it is necessary, in Applications of Satellite and Airborne Image Data to Coastal Management, edited by A.J. EDWARDS (UNESCO, Paris), 121-136.

FERGUSON, R.L. and K. KoRFMACHER (1997): Remote sensing and GIS analysis of seagrass meadows in North Carolina, U.S.A., Aquat. Bot., 58, 241-258.

Holden, H. and E. LeDREW (2002): Measuring and modeling water column effects on hyperspectral reflectance in a coral reef environment, Remote Sensing Environ., 81 (2-3), 300-308.

JAIN, S.G. and J.R. MiLLER (1977): Algebraic expression for the diffuse irradiance reflectivity of water from the two-flow model, Appl. Opt., 16 (1), 202-204.

LOUCHARD, E.M., R.P. REID, F.C. STEPHENS, C.O. DAVIS, R.A. LEATHERS and T.V. Downes (2003): Optical remote sensing of benthic habitats and bathymetry in coastal environments at Lee Stocking Island, Bahamas: a comparative spectral classification approach, Limnol. Oceanogr, 48 (1), 511-521.

LyZENGA, D.R. (1978): Passive remote sensing techniques for mapping water depth and bottom features, Appl. Opt., 17 (3), 379-383.

LYZENGA, D.R. (1981): Remote sensing of bottom reflectance and water attenuation parameters in shallow water using aircraft and Landsat data, Int. J. Remote Sensing, 2 (1), 71-82.

Mumby, P.J., C.D. Clark, E.P. Green and A.J. Edwards (1998): Benefits of water column correction and contextual editing for mapping coral reefs, Int. J. Remote Sensing, 19 (1), 203-210. 